\title{
Leveraging Virtual Learning Environments to Strengthen Pre-Service Early Childhood Teacher Preparation: Program Pivots Due to COVID-19 Empowers Future Practice
}

\author{
Lea Ann Christenson \\ Hannah Cawley \\ Janese Daniels \\ Department of Early Childhood Education \\ Towson University, Maryland, USA
}

\begin{abstract}
This critical reflection illuminates the planning, delivery, and evaluation of the 'pivots' an early childhood teacher preparation program made in response to the shift to virtual learning necessitated by the lock down measures prompted by the COVID-19 pandemic. The challenge was to shift two undergraduate courses from in person to a virtual format, including an inperson internship to an entirely virtual experience while maintaining a high-quality program which meets the certification requirements and professional standards. The process of moving the courses and internship to a virtual setting gave us the unique opportunity to step back and reflect on the essential conceptual knowledge and understandings necessary for teacher candidates to meet professional standards leading to certification and to becoming competent and caring professionals. Results of our critical reflection include lessons learned by the two instructors and department chair on the effective leveraging of technology to meet the challenges posed by COVID-19 leading to modifications to our program post pandemic.
\end{abstract}

Keywords: Teacher Education, Early Childhood Education, Clinical Experiences, Virtual Learning Environments

\section{Introduction}

March 11, 2020 is a day that will be long remembered around the world; it was the day that the World Health Organization (WHO) characterized the growing number of people infected around the world with COVID-19 as a pandemic. The WHO's announcement was followed shortly thereafter by the United States when a state of national emergency due to COVID-19 was declared. (Holland et al., 2020). Universities across the United States 
immediately began to transition to virtual instruction, as did Pre-Kindergarten- $12^{\text {th }}$ grade schools (i.e.: schools for 4-18 year-old students). This set of circumstances created a unique set of problems for university teacher preparation programs.

This unprecedented situation created challenges for teacher preparation programs as in this case the PreK- $3^{\text {rd }}$ schools in which the teacher candidates were placed in pivoted to virtual instruction and for the 2020-2021 academic year did not allow any type of internship experience in person or virtual. The instructors were not informed until a week before the semester started. Illuminated here are the steps the instructors and department chair took to make systematic programmatic changes in order to leverage technology to deliver instruction and to create meaningful virtual courses and internships. Also included are the lessons learned while making adaptations to the program while maintaining high quality. Our critical reflection revealed changes that support the conceptual strength of the program and those that will be maintained when in person instruction resumes.

\section{Context}

The program in the Department of Early Childhood Education, is one of seven programs in the College of Education at a large state university, which is the largest supplier of teachers in the state. The main goal of the department is to prepare graduates to meet the needs of all young children birth to age 8 by providing graduates with a comprehensive knowledge base of all aspects of early childhood (Darling-Hammond, 2000; Cochran-Smith, 2003). This is summed up in the mission of the Department of Early Childhood Education:

Towson University has been a leader in teacher preparation for over 150 years, and its programs are recognized for their high quality and innovation. The Department of Early Childhood Education provides a comprehensive academic program, combined with the valuable internship experiences you need to understand how young children develop and learn. (https://www.towson.edu/coe/departments/earlychildhood

\section{Our Program Before COVID-19}

Prior to the disruption related to COVID-19, our program functioned as a fully face-to-face program with in-person internships in Pre-K- $3^{\text {rd }}$ grade classrooms. After completing the general education requirements for the university, our teacher candidates spent one semester completing professional prerequisite courses. During this semester, they applied for formal admission into the Early Childhood major, having earned a minimum grade point average and having completed all prerequisite coursework. Upon program admission, our 
teacher candidates complete a three-semester sequence of coursework, including clinical experiences in partner schools, which would lead to a full-time 16-week student teaching internship.

Our three-semester sequence was designed to gradually increase the teacher candidate's experiences and time spent in our partner schools. The first semester consists of campus-based coursework and a 1-day/week clinical internship experience in a Pre-K or kindergarten classroom. During this semester, our candidates begin to experience being part of a school culture, learning how to work with other professionals in the building (e.g., resource teachers, special educators, building administrators).

Our candidates also begin to experience curriculum planning, assessment of children, and how to work directly with families. All of this is done under the guidance of an experienced mentor teacher and university supervisor. During the second semester of the Early Childhood program, our candidates continue their campus-based coursework, but they spend two days each week in a clinical experience, working in a first, second, or third grade classroom. Our candidates take on more responsibility and are expected to increase their competence and confidence as emerging early childhood educators. This semester culminates in a week-long experience that we call Teach Week. The third, and final semester of our course sequence is what has been traditionally known as student teaching. Our program identifies this as the fulltime clinical internship. During this semester, there is a shift from campus-based coursework to eight weeks of full-time work in a Pre-K or Kindergarten classroom and eight weeks of fulltime work in a first, second, or third grade classroom.

Our candidates take one course weekly on campus, Senior Seminar. The objective for the seminar course is to provide a space for our candidates to synthesize their experiences from the entire three semester sequence and discuss and debrief the full-time clinical internship experience. Our teacher candidates take on greater amounts of responsibility in their partner schools and take over full instruction from the classroom mentor teacher at the end of each two full-time clinical experience.

\section{Theoretical Framework}

Anchored by the National Association for the Education of Young Children's Professional Preparation Standards (NAEYC, 2011), our overarching goal is to ensure that our teacher candidates gain a deep understanding of and experience grounded in early childhood theory and practice of Piaget, Vygotsky, Clay, Bloom, Gardner, etc. (Beloglovsky, M., 2015). The NAEYC Professional Preparation Standards are comprised of seven standards, each of 
which has three to six key elements that help clarify what is expected for the standard. The standards and key elements are integrated throughout our Early Childhood Program and provide opportunities for our teacher candidates to demonstrate what they know, understand, and are able to do in relation to the standards.

These theories converge in the NAEYC standards with Developmentally Appropriate Practice (DAP) as the foundation to actualizing the Standards. DAP is characterized by a strength-based lens of young children which builds on their curiosity and interests through hands on instructional strategies and learning activities facilitated by teachers. (NAEYC, 2011). We believe that our graduates leave us prepared to teach all children and to work with all families, regardless of race, gender, ethnicity, or socioeconomic status.

Our program is grounded in the belief that our teacher candidates should understand and be able to apply developmentally appropriate practices when working with young children and their families. As such, our candidates take coursework and engage in deep conversations across our programs about how theory applies to their work with young children, birth to age 8 and look for the application of theory when they are participating in their clinical internship experiences.

\section{COVID-19}

COVID-19 changed our program's traditional plans! Midway through the Spring 2020 semester, we began to learn that our campus would experience an abrupt shift to $100 \%$ virtual instruction and that our partner schools would also be shifting to $100 \%$ virtual learning. This began about the second week of March 2020. Our teacher candidates had only had about four weeks of a 1-day/week internship experiences in their placements. The semester finished with virtual classes and assignments created to make up for lost time in school placements.

\section{Planning for Fall 2020}

During Summer 2020, we waited for guidance from our district partners and our university as to how learning and clinical experiences for our 1-day/week teacher candidates would occur during Fall 2020. As we got closer to the start of the semester and the school year, it became clear that our teacher candidates would not be entering public schools for clinical internship experiences either in person or virtually.

Our school district partners began the year with $100 \%$ virtual learning and decided to only give virtually placements to student interns in their professional year. This decision was made in mid-August and left Term 6 students without any placement or connection to children 
and families in public schools.

After this last-minute decision, the faculty and department chair began to think creatively about how we could provide a meaningful experience to our 1-day/week candidates. The goal was to determine how the early childhood program could support learning for the cohort and how the program could provide a meaningful experience for the cohort in spite of the fact that cohort members, teacher candidates, would not be able to participate in the traditional public school internship experience.

What grew out of these meetings and critical reflection was a collaboration with the university faculty, individual partners from the early childhood profession, and an emerging program in partnership with the University Child Care Center (UCCC). In the next sections, we will describe the outcomes that grew out of our desire to provide meaningful experiences for our cohort and we will share lessons learned as we reimagined our Early Childhood program.

\section{Our Program Reimagined}

Planning Process and Shift to Online Learning

So then, what do you do when a few weeks before the semester is to begin, you are informed that the planned internship in public elementary schools for your college students was cancelled due to a global pandemic? After we got over the shock and panic, we began to brainstorm ideas for virtual experiences that would be meaningful for both our teacher candidates and young children.

We were grateful for colleagues willing to walk this walk with humor, integrity, creativity, flexibility, and an ardent desire not to give up, but to create something rich and meaningful. The expression "building a plane while flying it" was something frequently thought and occasional said at the beginning of the semester. Although we possess experience and background knowledge, this was completely new and changing daily based on the health risks of the pandemic and uncertainty surrounding closures and stay-at-home orders.

Our university began Fall 2020 with the intent of having some classes meet in person. Within days of students returning to campus, and out of an abundance of caution, the university moved all classes online and students living in the dorms returned home. So now, the faculty had no placements for one course and had to pivot to on-line learning with no notice. The campus remained open and faculty who wanted to teach from the technology-equipped classrooms were welcome to report to campus to do so and we decided to come to campus and team teach from our classroom. 
We met daily and weekly, before and after class, in person to collaborate and plan with guidance and support from our department chair. The department chair informed us she would report to campus to work in her office on the days we taught on campus. She felt that we, the course instructors, were making an important statement by coming in to work each week to team teach and broadcast from the classroom, and she wanted to demonstrate her support for our efforts by being physically present and available for us.

This provided us with a way to collaborate in person...we missed being around people! Co-teaching from our classroom gave us much needed, safely distanced social interactions and it provided a model for our teacher candidates on how to work with colleagues in the face of what could seem to be impossible circumstances. By November, the COVID-19 infection rate rose to a point where we did not believe it would be safe for even the instructors to meet in person and we moved our planning on-line.

\section{Adapting Course Assignments to Online Learning}

\section{One Day a Week Internship.}

With schools closed due to the global pandemic and access to our mentors denied, our challenge was to create a meaningful internship experience to take the place of the one day a week internship for our teacher candidates. All of the coursework listed above has a field component where the teacher candidates practice what they are learning in their Term 6 courses under the direct guidance of a mentor teacher and university supervisor. What could be put in place that would be meaningful and provide practical, hands-on experience?

\section{Family Engagement.}

In addition, to being placed in school setting during Term 6, one of requirements to meet NAEYC Standard 2: Building Family and Community Relationships was for our teacher candidates to have experience and build confidence working directly with families and design meaningful family engagement events. In the past, our teacher candidates have planned and implemented a variety of family engagement activities based on the school improvement plan and specific goals expressed by school administrators and mentor teachers.

Our students are responsible for all aspects of planning, facilitate the event and follow up to determine the impact this had on families. We have had many successful programs in past semesters. Some examples include "Donuts with Dads", where student interns worked on take-home packets to increase math skills during the summer break, World Earth Day, where our student interns created a school-wide, community-wide clean-up day to beautify the building grounds, and make $\&$ take literacy projects, which were shared with families during 
the school's spring festival. However, with school closures these types of in person events could no longer take place. So now what?

Answer: Family Engagement Sessions: A Virtual Internship with Children and Families.

At our university we are fortunate to have a premiere childcare center that serves faculty, children, and the greater community. The director of the childcare center works closely with the College of Education and welcomes our teacher candidates for observations. Many college students work part time at the childcare center assisting classroom teachers. The pandemic drastically reduced the number of young children who could be at the center and at times, the center was forced to completely shut down.

In Fall 2020 the center was open to a reduced number of children. The director explained many of her families who were now at home with their toddlers and preschool aged children had expressed a desire to stay connected with the childcare center even though they were not ready to send their children to the center in person and were looking for enrichment activities for their children. This was the beginning of our partnership and reinvented virtual internship. The decision was made to partner with families from the childcare center and work with them weekly to enrich their experiences while at home with young children during the pandemic. Each of our teacher candidates was assigned to two children and their families and planned weekly learning adventures based on the themes provided by the childcare center and specific needs and interests of their students. We explicitly taught the planning process and provided a guide (Appendix I). This guide was turned in weekly as well as a reflection after the session. The instructors provided feedback on the planning guide and reflection.

\section{How did we accomplish this?}

1. Connecting our student interns with children and families by having the childcare center director send inquires to families

2. Once the partnership with families was forged, letters were sent home inquiring about their child's interests and aptitudes. Additionally, we wanted to learn about the families themselves to understand the child's home environment.

3. Limited the time young children were on the computer to 30 minutes. This time included a read aloud and follow-up activities including music and movement. Suggestions for extension activities were provided ahead of time by emailing the families with materials that expanded the learning beyond the 30-minute session.

4. Created a family engagement planning guide for each learning session that included the theme, vocabulary words, aligned with College and Career Readiness 
Standards for Math and (English Language Arts) ELA, and documented an interdisciplinary connection.

5. Required teacher candidates to write a reflection after each session documenting their successes and challenges and what they would do differently in future sessions. Additionally, the teacher candidates were required to document their assessment strategies.

6. Followed-up with a survey to families to provide us with feedback for future planning.

7. As a final reflection we had our teacher candidates align their family engagement experience with the NAEYC Standards for Early Childhood Professional Programs.

By the end of the semester, each teacher candidate had facilitated 20 virtual family engagement sessions. They applied technology in a new way to connect with families. They had planned and reflected on the experiences and extended the connections with families by emailing before and after the sessions. They connected with families sometimes during the sessions but always before and after.

We received positive feedback from the families directly to our department and through the childcare director (Appendix II). Many of our teacher candidates went above and beyond and created backgrounds related to the theme for visual appeal and engagement.

\section{Prop Box}

Another long-standing assignment which supports all of the NAEYC Standards is the dramatic play prop box, where teacher candidates use raw materials and their imaginations to create engaging Social Studies and Science learning activities built around themes which also support the English Language Arts (ELA) and Math standards. Examples of past prop boxes have been community helpers, gardening and a trip to the vet, all designed for young children to learn more about the topic while engaged in playful learning.

In the past, after an introduction of the prop box and modeling how to use the materials, our teacher candidates leave the prop box in the classroom and allow the children to engage with those materials while observing how they interact and learn from these activities. Our teacher candidates are encouraged to recycle or upcycle, find creative ways to reuse materials that may otherwise be thrown out, or to use materials they find in their homes or places of work, yard sales and other cost sensitive ways to build a thematic box that is safe, authentic and engaging for the young children. 
With the current pandemic, this has been a challenge and something else that we have had to reimagine. It has taken on a different form as we want our teacher candidates to stay safely at home and not out shopping or exploring putting themselves at unnecessary risk of exposure to the COVID-19.

We were forced to have our teacher candidates create virtual props boxes and share them with peers and not children. We accomplished this by creating a PowerPoint template for our teacher candidates to complete and asked them to include items they had readily available in their homes or virtual items they found exploring the internet.

Our teacher candidates put together a meaningful assorted of materials and activities centered around the prop box theme. We had our them present to their peers in smalls groups and required them to provide meaningful written feedback to each other. Our teacher candidates took this feedback to enhance their final project that was submitted virtually a week later. Once the PowerPoint and written materials were submitted, the teacher candidates presented their prop boxes to the faculty on an individual basis. This was an ongoing project where teacher candidates used feedback and suggestions to improve their final product. Breakout rooms during our class time enabled us to do this from the safety of home and as instructors we were able to join each group to answer any questions that may arise. Part of the assignment was focused on how these materials could be used effectively in a virtual environment and our teacher candidates used these materials to support their family engagement sessions.

\section{Specialist Interview}

In past semesters, our teacher candidates have selected one school specialist at their internship and interviewed them to learn more about their job and how they served children and families. One of the unexpected benefits of virtual learning was being able to invite a vast array of guest speakers to join our class. We did not need to worry about parking passes or stipends as speakers joined our class during the workday from their virtual workspace.

Every week of the course we invited an educational professional to share their experience and expertise and giving our students words of encouragement and advice. It was a highlight of the course for both instructors and teacher candidates. We had presentations ranging from a Pre-K-mentor teacher from one of our partner schools, a pediatric nurse, a director of a public childcare center, a school counselor, a principal, a community school coordinator, a music teacher, a private pre-school director, and an outdoor education specialist. We were humbled by how all of these professionals graciously shared their time and expertise 
with our future educators. It was evident that they spent time preparing for their presentations and were passionate about the work they do in service of young children.

However, during the pandemic and because so many professionals were working from home, we were able to hear directly from more specialists than ever before. It was motivating to hear from so many people dedicated to improving the lives of children. We were frequently struck by the common themes from all our specialists, echoing what we stress with our teacher candidates. One theme being the importance of building relationships and another theme was to remain positive and surround yourself with like-minded, positive people.

All our specialists conveyed the importance of dedication, commitment, and passion for their jobs. It invigorated us to hear directly from educational professionals working tirelessly to serve children. We hope to continue to include this in our course when we return to in person learning. The use of guest speakers virtually opened the world of teaching to our students beyond the walls of our university and their single classrooms and schools. We were able to bring in a diverse cross section of educational experts in many different contexts: a variety of schools with varying demographics, leaders at the school district and state level and disciplines; music education, speech therapy, pediatric nurse, etc. Technology literally brought the world into our university classroom via zoom and we intend to continue to do so when we return in person.

\section{Lesson Observation Critiques}

In addition to modifying assignments created for brick-and-mortar classrooms, we the instructors, added assignments to help our teacher candidates deconstruct in person teaching. Because our teacher candidates would not be in classrooms; Lesson Observation Critiques assignments were added which included asynchronous class time spent viewing videos of exemplary teaching in pre-Kindergarten and kindergarten settings with guided reflections to assist the students in deconstruction of best practices. This assignment was then deconstructed in during synchronous class each week via whole and small group instruction. The discussions included ways in which these best practices could be implemented in the family engagement sessions.

\section{Discussion}

The course instructors and the chair of the department met and communicated several times a week over the course of the semester to reflect on how the changes to the program were going and to make changes as necessary as the class was in flight. Due to being notified in late 
August that our Term 6 teacher candidates would not have access to mentors in partnership schools, planning for the Family Engagement sessions and Lesson Observation Critiques continued after the semester started in late August until mid-September.

As a result, due dates became more fluid over the course of the semester than they were in the past. Some teacher candidates used the extra time however, most adhered to the original deadlines while maintaining a high level of professionalism completing their assignments. There was a sense of collaboration and cooperation between the instructors and teacher candidates that had not been present in earlier semesters. Herein are the lessons learned over the course of the semester.

\section{Family Engagement Sessions}

These sessions met two objectives. First, to take the place of the one day a week internship and second to take the place of the Family Engagement assignment which traditionally was helping with an after-school event such as a Literacy Night or Back to School Night. For all stakeholders, the family engagement activities were a success. The children and families stayed connected to the childcare center and were provided with developmentally appropriate academic support.

The university students were provided with an intimate experience getting to know and serve families. This type of family engagement was much more personal than the traditional Science Nights as they literally had an intimate window to how families operate...during a pandemic! The level of planning the teacher candidates were required to do was much more detailed than in the typical one day a week semester where they pretty much just shadowed a mentor.

This assignment helped build confidence and a sense of efficacy in the teacher candidates. The had much more responsibility earlier in the program and most appeared to thrive under these expectations. We hope to continue these on-line sessions and leverage the learning from them.

Appendix II provides a few of the positive unsolicited comments from some of the participating families. At the time of writing, the instructors are conducting a systematic survey of all the participating families.

As was mentioned earlier, teacher candidates take a total of six courses during Term 6 and in the past, all have had assignments linked to placements in schools. The instructors in most of the courses in the absence of placements due to COVID-19 during Fall 2020 took advantage of the teacher candidates' access to children and families through the Family 
Engagement sessions and tailored some of their instruction and assignments to support these sessions. Thus, the work done by the ECED 341 and ECED 343 instructors benefited all of the courses.

In Spring 2021 we expect to still be in an all-virtual environment, so we will continue this partnership with the University Child Care Center. We are also in preliminary conversations with a public school that has a 'Judy Center' that serves children and families near the poverty line about how our students can serve that program virtually.

This iteration of Family Engagement better meets NAEYC Standard 2, Building Family and Community relationships and Standard 7 Field Experiences as the teacher candidates were now exposed to the $0-3$-year-old setting in ways in which they had not before. In the future, in preparation for going back to a face-to-face reality, we will be in discussion with all stakeholders to investigate the possibility of continuing the partnership during Term 6 with childcare centers.

\section{Prop Box}

Although the modifications to the Prop Box assignment were not as extensive as the Family Engagement and the one-day placement, the outcome was quite positive. Overall, there was greater level of creativity and more diverse and meaningful materials found in their homes and virtually on the internet. Providing the time and space during class created a climate of cooperation, not competition and allowed for direct feedback prior to final submission and grading.

In the past, some of the Prop Boxes were very formulaic and cookie cutter. Some teacher candidates spent so much time on making their box 'cute' that they lost sight of the purpose of the materials: to teach literacy and math skills through a theme in developmentally appropriate ways.

In this way NAEYC Standard 4: Using Developmentally Effective Approaches and Standard 5 Using Content Knowledge to Build Meaningful Curriculum were met in a much more authentic and meaningful way. We intend to use this more collaborative approach moving forward in a virtual or eventual face-to-face modality.

Specialist Interviews

This new iteration of this assignment is another 'keeper'! In the past, our teacher candidates got an up-close view of only one specialist in the school in which they were placed. In this virtual format, they learned from no fewer than 15 specialists, located in a wide variety of settings in and out of schools. This provided for a much richer and informative perspective on which to build their final semester in the program and as beginning teachers. Each guest 
speaker finished their presentation with advice to those starting out in the profession. Through subsequent discussions both in small groups and whole class, as well as a final summative reflection, the teacher candidates demonstrated a much greater level of expertise about school and communities holistically in support of young children and their families.

This iteration of the assignment gives greater support to NAEYC Standard 1: Promoting Child Development and Learning and Standard 6: Becoming a Professional. Moving forward both in a virtual and face to face platform, we are going to continue with this much more meaningful version of the specialist interview assignment. The challenge once we return to face to face may being able to secure speakers, primarily because they will have returned to their buildings/offices. However, we are now experts at interfacing with on-line platforms so that will be very likely how we will interact with these varied experts into our university classrooms.

\section{Lesson Observation Critiques}

The Lesson Observation Critiques were the only new assignments we added to our course. The above-mentioned assignments were revisions of existing assignments. The Lesson Observation Critiques proved to be a valuable addition as they provided a window in on faceto-face classrooms which the teacher candidates will one day be hopefully interning in and most certainly be teaching in as in-service teachers.

We strategically chose the lessons they needed to be exposed and then support the viewing with readings, reflection questions and in class discussions to help our teacher candidates deconstruct what they had viewed. Furthermore, we encouraged them to incorporate these face-to-face strategies where applicable to their virtual Family Engagement sessions to give them immediate practice with these skills.

The Lesson Observation Critiques helped support NAEYC Standard 3: Observing, Documenting, and Assessing to Support Young Children and Families, Standard 4: Using Developmentally Effective Approaches, Standard 5: Using Content Knowledge to Build Meaningful Curriculum and Standard 7: Field Experiences.

Moving forward, even when the teacher candidates are back in schools, we plan on incorporating Lesson Observation Critiques to some degree. These strategically selected videos and reflections helped us systematically guide our teacher candidates to best practices for young children instead of leaving their discovery to chance in their placements. Through these videos the instructors were able to systematically and strategically connect early childhood theory via the NAEYC standards to actual classroom practice. This will assist the interns once they return to in person classrooms to better make these theoretical connections themselves. 
When they are back in schools, we will use these videos and reflections to guide and reflect on the practices they observe firsthand.

\section{Conclusion}

There is no doubt that the COVID-19 pandemic has presented all of us with challenges and it seems that everyone has lost something important to them during the pandemic and early childhood classrooms (Soltero-Gonzalez, 2021) and university teacher preparation programs for early childhood educators are no exception (Nazerian, 2020). However, along with the loss there was renewal and hope. Through our process of critical reflection, the instructors and chair of the department found solutions to the problems the pandemic created that were in line with the essential conceptual understandings necessary for teacher candidates to become competent educators (Jones, et al., 2021). We used technology in new ways for us, virtual classes and Family Engagement Sessions as well as video.

A solution to a problem however, also a way to continue to be better at preparing future educators for DAP (NAEYC, 2011) instruction to meet the needs of all young children (Egan et.al, 2021). In our program we all: instructors, students and the department chair were in this unique and sometime scary situation together, and we helped one another through the semester while maintaining academic integrity around the content of the courses.

We made shifts to the virtual world of instruction and internships while using the NAEYC Standards as a lens the changes we made. Hopefully, as a university faculty we modeled the strong content knowledge, flexibility, integrity, respect for our students and love of the act of teaching no matter the environment for our students. All of which are the hallmarks of competent and successful educators of young children.

\section{References}

Beloglovsky, M. (2015). Early learning theories made visible. Minnesota: Redleaf Press. Cochran-Smith, M. (2003). Teaching quality matters. Journal of Teacher Education, (2), 95.

Darling-Hammond, L. (2000). Teacher quality and student achievement. Education Policy Analysis Archives, 8(1), 1-44. doi:http://dx.doi.org/10.14507/epaa.v8n1.2000

Egan, S. M., Pope, J., Moloney, M., Hoyne, C., \& Beatty, C. (2021). Missing Early Education and Care During the Pandemic: The Socio-Emotional Impact of the COVID-19 Crisis on Young Children. Early Childhood Education Journal, 49(5), 925. https://doi.org/10.1007/s10643-021-01193-2

Holland, S., Mason, J., and Brice, M. (2020, March 13). Trump declares coronavirus national 
emergency, says he will most likely be tested. Reuters. https://www.reuters.com Jones, D., \& Defending the Early Years (DEY). (2020). The Impact of COVID-19 on Young Children, Families, and Teachers. Defending the Early Years.

Nazerian, T. (2020). LOOKING AHEAD: Four ways 2020 might shape the future of teacher prep. Literacy Today (2411-7862), 38(3), 26-29.

National Association for the Education of Young Children (NAEYC) Professional Preparation Standards, (2011)

Soltero-González, L., \& Gillanders, C. (2021). Rethinking Home-School Partnerships: Lessons Learned from Latinx Parents of Young Children During the COVID-19 Era. Early Childhood Education Journal, 49(5), 965.

\section{Appendix I}

\section{Family Engagement Planning Guide}

Lead Teacher:

Date of session:
Assistant Teachers:

Time of session:

Name, age and characteristics of child:

1. Theme of session:

2. Overall objective:

3. Target Academic Vocabulary (list 5-8 words)

4. MSCCR: (English Language Arts) ELA Maryland Standards for College and Career Readiness English Language Arts OR Maryland Early Learning Standards for Language and Literacy

(list 2-4 standards)

5. MSCCR: Math (list 1 or 2 standards)

6.

7. Interdisciplinary connections: (circle those that apply and explain)

Social Studies $\quad$ Science The Arts Other

8. Music/poem: 
9. Movement:

10. Learning game(s):

11. List Read Aloud or Shared Reading Book (title and author):

12. List a minimum of 5 comprehension questions for Read Aloud or Shared Reading (easy to complex)

13. What specific strategies will be used to engage children during session?

14. Materials (for you and for the child at home):

15. Extensions for Family at home (explain here and provide guidance in email to family after session) Art, Developmentally Appropriate writing activity, Guided Outdoor Activity, Other:

\section{Appendix II}

\section{Sample Comments from Participating Families}

These unsolicited comments were collected by the Director of the Child Care Center from participating families.

"We just had our session with the three Towson students and they NAILED IT! My child (age 2 and a half) loved their choice of books, songs, and activities. It was like having his own personalized story-time."

"My child (age 3) was so excited to be meeting with the Towson students again, she asks in the morning if today is the day. The students were extremely engaging and good at their work. What a lovely idea. Hooray!!"

"Just a quick note to say that our family's student interns are doing SUCH AN AMAZING JOB preparing for and executing their sessions with my child (age 3 and a half). I 
was with them last week and now they are meeting with him and my husband."

"What they planned both times is super age-appropriate, fun and aligned to her (age 3 ) interests. They are doing great at communicating warmth, energy and interest via the screen and she loves the experience. So excited to see this in action!"

\section{Authors}

Lea Ann Christenson, PhD is an Associate Professor in the Department of Early Childhood Education at Towson University, and her research interests include teacher professional development in urban and international settings, early literacy, and STEM. She taught Kindergarten-second grade and ESOL and was an Assistant Principal in California public schools.

Hannah Cawley, MA is a lecturer in the Department of Early Childhood Education at Towson University and has expertise in the areas of Curriculum and Instruction, Human Growth and Development and Developmentally Appropriate Practice for young learners. She applies her expertise in her work with pre-service teachers in urban settings.

Janese Daniels, PhD is the Chair and a Professor in the Department of Early Childhood Education at Towson University, and her research interests include family literacy practices, Head Start programs, at-risk families, and technology use in the early childhood classroom. She also has written book chapters on literacy and presented work on the integration of technology in education at national conferences. 